\title{
ANALISIS HUBUNGAN PERSEPSI MAHASISWA TENTANG KOMPETENSI PEMBIMBING AKADEMIK DALAM BIMBINGAN DENGAN KEPUASAN MAHASISWA DALAM PROSES BIMBINGAN DI PRODI DIII KEPERAWATAN TANGERANG 2015
}

\author{
*Suyatini, *Parta
}

\begin{abstract}
Abstrak
Pembimbing Akademik merupakan kunci keberhasilan mahasiswa dalam akademik, Psikologis maupun Sosial, institusi pendidikan mempunyai tanggung jawab sepenuhnya untuk membantu seluruh mahasiswa agar mampu menghadapi segala tantangan yang timbul. Hasil penelitian Sugiarto tahun 2005 didapatkan kompetensi pembimbing akademik pada Prodi Kep tinggi (42,5\%) rendah (57,5\%), dari hasil observasi ternyata tatap muka pembimbing akademik dengan mahasiswa dilakukan pada saat tertentu saja (pengisin KRS, Pengambilan KHS dan apabila ada masalah), Rumusan masalah: adalah Bagaimana persepsi Mahasiswa tentang kompetensi Pembimbing Akademik?, dan apakah ada hubungan antara kompetensi Pembimbing Akademik dengan Kepuasan mahasiswa dalam proses bimbingan di Program Studi DIII Keperawatan?. Tujuan penelitian: untuk mendapatkan informasi persepsi mahasiswa tentang kompetensi Pembimbing Akademik dihubungkan dengan kepuasan mahasiswa dalam proses bimbingan, Manfaat Penelitian: Hasil penelitian dapat dimanfaatkan oleh Direktorat, Prodi keperawatan dan Pembimbing Akademik. Desain penelitian adalah observasional, dengan pendekatan Cross Sectional, penelitian dilakukan pada prodi DIII Keperawatan Tangerang, populasi adalah seluruh mahasiswa DIII Keperawatan sedangkan besar sampel diambil mahasiswa Tingkat II dan Tingkat III sebanyak 76 orang Hasil Penelitian; Dari 76 Responden yang mempersepsikan kompetensi Pembimbing Akademik tinggi dalam melakukan bimbingan secara proporsional berpeluang untuk mendapat puas lebih tinggi 82,5\% (33Mhs) dibanding dengan mahasiswa yang tidak puas sebesar 17,5\% (7Mhs) hasil uji Statistic dengan menggunakan uji Chi Square didapatkan Nilai $\mathrm{P}=0,000$ artinya ada hubungan yang signifikan antara kompetensi Pembimbing Akademik dalam bimbingan dengan tingkat kepuasan mahasiswa ,Kesimpulan: Mahasiswa yang mempersepsikan Pengetahuan Pembimbing Akademik dalam melakukan bimbingan tidak memadai memiliki proporsi lebih besar yaitu 51,3\% (39 Mhs) dibanding dengan yang mempersepsikan memadai sebesar 48,7\% (37Mhs), Adanya hubungan yang Signifikan antara kompetensi Pembimbing Akademik dalam bimbingan dengan kepuasan mahasiswa
\end{abstract}

\section{Kata kunci : Pimbimbing Akademik, Kopetensi, Kepuasan}

*Jurusan Keperawatan Poltekkes Kemenkes Banten 


\section{Pendahuluan}

Parsono (1999) menyatakan bahwa lembaga pendidikan mempunyai tanggung jawab sepenuhnya untuk membantu seluruh peserta didik (mahasiswa) agar mampu menghadapi segala tantangan yang timbul setiap saat dalam proses pembelajarannya.

Pembimbing Akademik adalah dosen tetap yang ditetapkan dengan keputusan Direktur pada institusi pendidikan yang berfungsi memberikan bimbingan belajar dan membantu memecahkan masalah yang dihadapi dan berpengaruh terhadap proses pembelajarannya termasuk masalah pribadi, keluarga dan lainnya (Depkes 1998), Pembimbing Akademik merupakan kunci keberhasilan mahasiswa baik dalam Akademik, Psikologis maupun Sosial (Anton Sukarno,1990).

Kepuasan konsumen/mahasiwa adalah tingkat perasaan konsumen/mahasiswa setelah membandingkan apa yang dia terima dengan harapannya (Umar dalam Kajian pustaka, 2005). Hasil penelitian Sugiarto Kompetensi Dosen tinggi (42,5\%) dan rendah (57,5\%), Dari hasil observasi bimbingan Pembimbing Akademik dilakukan hanya pada waktu tertentu (pengisian KRS, pengambilan hasil KHS dan jika mahasiswa bermasalah

\section{Metode Penelitian}

Metoda yang digunakan dalam penelitian adalah analisis yang bersifat observasional untuk melihat hubungan antara variable independen terhadap variabel dependen, data diambil secara cross sectional untuk mengukur faktor yang mempengaruhi kejadian asfiksia data dan informasi diperoleh dari Rumah Sakit Umum
Kabupaten Tangerang Banten, waktu penelitian dilaksanakan pada bulan Juli - Agustus 2013

Populasi dalam penelitian ini adalah seluruh bayi yang lahir di rumah sakit umumTangerang pada tahun 2013

Sampel diambil sesuai rumus pendugaan proporsi (Lameshood,Hosmer.Jr 1997) sampel dalam penelitian ini adalah bayi yang lahir di rumah sakit umum Tangerang dengan cara non probability sampling (quota sampling) yaitu setelah ditentukan sampel yang akan diambil, kalau jumlah sampel sudah tercapai maka pengumpulan data dihentikan dan hasil segera diaanalisis.

Berdasarkan rumus diatas maka besar sampel minimal 185 bayi

Kriteria Inklusi :Bayi yang lahir di Rumah Sakit umum Tangerang,Ibu Yang melahirkan di RSU Tangerang,bu yang bersedia menjadi responden dan menandatanganni Informed Consent

Teknik Pengumpulan data .

Data adalah data primer dikumpulkan langsung oleh peneliti dengan menggunakan Kuesioner, lembar observasi dan wawancara

\section{Manajemen Dan Analisa Data}

Maksud melakukan editing data supaya data yang diperoleh dapat diolah dengan baik sehingga dapat menghasilkan output yang merupakan jawaban terhadap hipotesa penelitian. Pada tahap ini peneliti memeriksa setiap instrument berkaitan dengan jawaban dan kejelasan hasil pengisian.

Koding data. Pada tahap ini peneliti menterjemahkan data yang diperoleh menjadi 
bentuk kode untuk memudahkan pengolahan data.

Entry data.

Setelah selesai memberi kode pada data dilanjutkan dengan memasukkan data dedalam computer ddan melakukan proses dengan program SPSS.

Cleaning data.

Dalam tahap ini peneliti melakukan pembersihan data yang sesuai dengan data yang diperlukan dalam penelitian dengan melakukan cek terhadap data yang telah dientry (dimasukkan ) dalam computer

\section{Analisa Data}

Setelah data terkumpul dilakukan editing data, koding, selanjutnya entery dan cleaning data, selanjutnya dilakukan analisa dengan menggunkan bantuan program komputer Analisa data meliputi :

Analisis univariat.

Untuk melihat karakteristik tiap variabel baik independen maupun dependensehiungga diketahui distribusi frekuensi setiap variabel yang berkaitan dengan penelitian.

Analisis bivariat.

Untuk melihat hubungan atau korelasi antara variabel independen terhadap variable dependen.Karena setiap variabel merupakan data katagorik dan memiliki 2 kriteria,maka analisis dapat menggunakan uji chi square $\left(\mathrm{x}^{2}\right)$.

Analisis Multivariat .

Untuk mengetahui variabel indevenden yang paling dominan berpengaruh terhadap varibel devenden, karena datanya data katagorik maka analisis menggunakan regresi logistik linear

\section{Hasil Penelitian}

Analisis Univariat;

Gambaran Karakteristik Ibu.

Karakteristik ibu terdir iparitas, KPD, PEB HAP, lama pesalinan, penyakit kronis, jenis persalinan Umur ibu dan pendidikan ibu dapat dilihat pada tabel 1

TABEL.1.

Distribusi karakteristik ibu di RSU Kabupaten Tangerang

Tahun 2013

\begin{tabular}{|c|c|c|c|c|}
\hline$\overline{\text { No }}$ & Variabel & Katagori & (185) & b \\
\hline \multirow[t]{4}{*}{1} & Paritas & 1. $=$ & 09 & 8,9 \\
\hline & & Resikotinggi & & \\
\hline & & 2. $=$ & 76 & 1,1 \\
\hline & & Resikorendah & & \\
\hline \multirow[t]{2}{*}{2} & PEB & $1=\mathrm{PEB}$ & 52 & 8.1 \\
\hline & & $2=$ Bukan PEB & 33 & 1.9 \\
\hline \multirow[t]{2}{*}{3} & HAP & $1=\mathrm{HAP}$ & 11 & 6.0 \\
\hline & & $2=$ Bukan HAP & 74 & 4 \\
\hline \multirow[t]{2}{*}{4} & Penyakit Kronis & $1=\mathrm{ada}$ & 11 & 6,0 \\
\hline & & $2=$ Tidakada & 74 & 4 \\
\hline \multirow[t]{2}{*}{5} & Umur ibu & $1=$ resikotimggi & 29 & 5.6 \\
\hline & & $2=$ resikorendah & 56 & 4,4 \\
\hline \multirow[t]{2}{*}{6} & Pendidikan & $1=$ rendah & 06 & 7.2 \\
\hline & & $2=$ Tinggi & 79 & 2,8 \\
\hline
\end{tabular}

\section{GAMBARAN KARAKTERISTIK BAYI}

\section{BARU LAHIR}

Karakteristik bayi baru lahir terdiri berat badan lahir bayi masa gestasi, kejadian asfiksia dapat dilihat pada tabel 2 
TABEL 2.

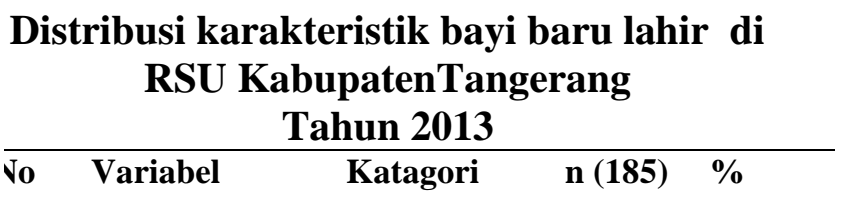

\begin{tabular}{lllll}
\hline 1 & Masa & $1=$ Dismatur & 51 & 27,5 \\
& gestasi & $2=$ Matur & 134 & 72.5 \\
2 & BBL & $1=$ BBLR & 20 & 10.8 \\
& & $2=$ BBL & 165 & 89.1 \\
& & normal & & \\
3 & Kejadian & $1=$ asfiksia & 44 & 23.8 \\
& asfiksia & $2 \quad$ non & 141 & 76.2 \\
& & asfiksia
\end{tabular}

Kejadian Asfiksia.

Dari 185 responden bayi yang lahir dengan asfiksia (nilai apgar< 7 ) sebanyak 44 orang $(23,8$ $\%)$ dan sebagian besar bayi yang lahir tidak terjadi asfiksia (nilai apgar $\geq 7$ ) sebanyak 141 orang $(76,2 \%)$.

\section{GAMBARAN KARAKTERISTIK}

\section{PERSALINAN}

Karakteristik Persalinan meliputi lama persalinan,jenis persalinan dan ketuban pecah dini dapat dilihat pada tabel 4.3

\section{TABEL 3.}

Distribusi karakteristik Persalinan di RSU KabupatenTangerang Tahun 2013

\begin{tabular}{lllll}
\hline No & Variabel & Katagori & $\mathrm{n}(185)$ & $\%$ \\
\hline 1 & Lama & 1 = Lama & 32 & 17,2 \\
& Persalinan & 2 = Normal & 153 & 82,8 \\
2 & $\begin{array}{c}\text { Jenis } \\
\text { Persalinan }\end{array}$ & $1=$ Persalinan & 80 & 43,2 \\
& & dgn tindakan & & \\
& $=$ & Spontan & 105 & 56.8
\end{tabular}

\begin{tabular}{|c|c|c|}
\hline$=\mathrm{KPD}$ & 80 & 43.2 \\
\hline$=$ Bukan KPD & 105 & 56.8 \\
\hline
\end{tabular}

Berdasarkan table 3 di peroleh informasi mengenai :

Lama persalinan

Dari 185 orang responden yang mengalami PK II lama (Parturien Kala II Lama) sebanyak 32 orang sedangkannsebanyak 153 orang $(82,2 \%)$ ibu tidak mengalami PK II lama Jenis persalinan

Dari sebanyak 185 responden yang melahirkan denganTindakan sebanyak 80 orang $(43,2 \%)$ sedangkan yang melahirkan secara spontan sebanyak 105 orang $(56,8 \%)$

Ketuban pecah dini( KPD)

Dari 185 ibu yang melahirkan yang mengalami ketuban pecah dini sebanyak 80 orang $(43,2 \%)$ dan ibu yang tidak mengalami KPD sebanyak 105 orang $(56,8 \%)$

\section{Hasil Analisis Bivariat}

Untuk mengetahui ada tidaknya hubungan karakteristik ibu (Paritas, PEB, HAP, penyakit kronis, Umur ibu dan pendidikan), karakteristik bayi (berat badan lahir, bayi masa gestasi) dan ppersalinan (lama persalinan, jenis persalinan .KPD) dengan kejadian asfiksia pada bayi di RSU kabupaten Tangerang tahun 2013.

Adapun hasil analisis bivariate dapat dilihat pada tabel 4. 


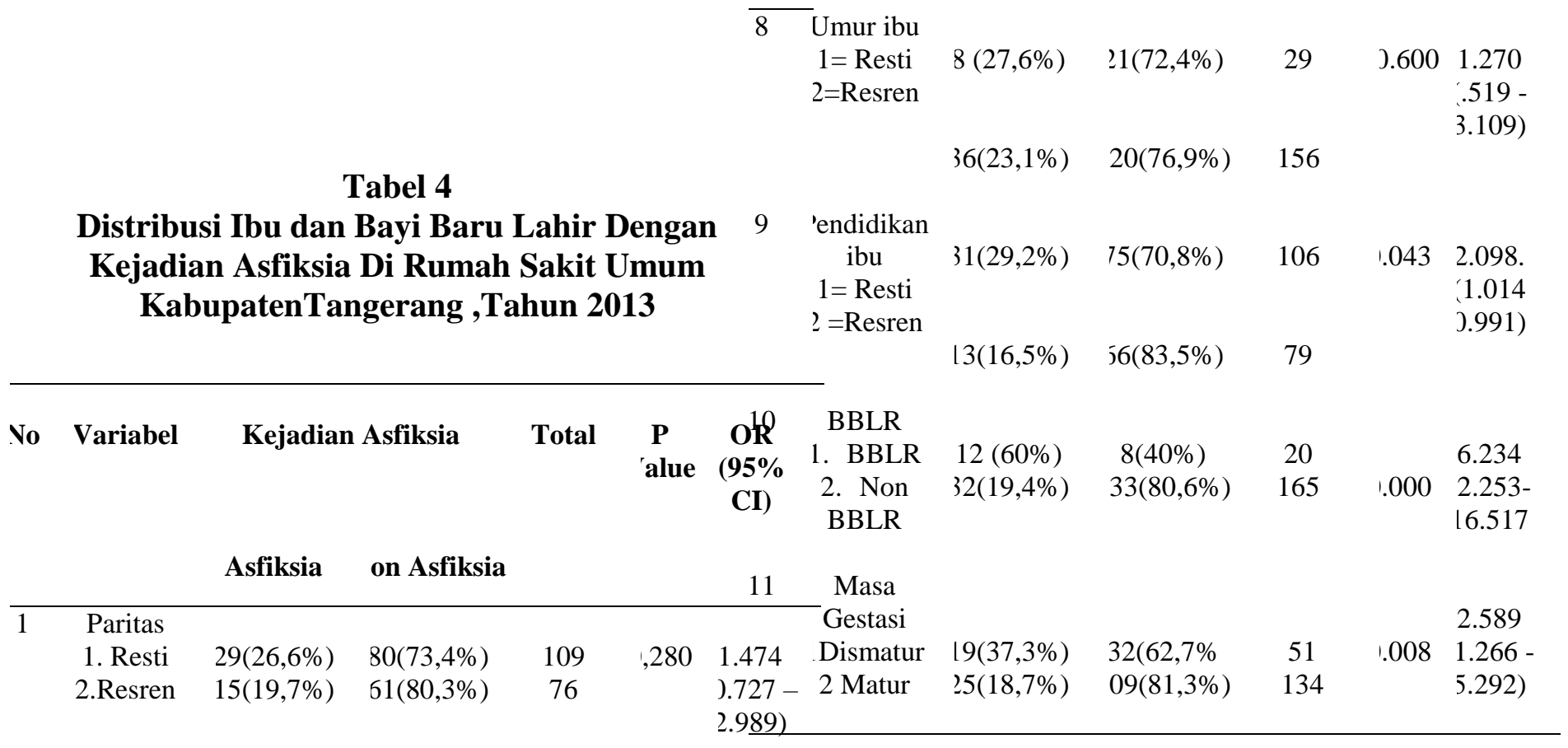

2 KPD

$\begin{array}{llllll}\text { 1.KPD } & 20(25 \%) & 60(75 \%) & 80 & 1.735 & 1.125\end{array}$

2.Tidak $\quad 24(22,8 \%) \quad 31(77,2 \%) \quad 105 \quad 0.569-$

KPD

3 PEB

1. PEB $\quad 17(32,7 \%) \quad 35(67,3 \%) \quad 52$

Tidak PEB $27(20,3 \%) \quad 06(70,7 \%) \quad 133$

4 HAP

$\begin{array}{lllc}\text { HAP } & 3(27,3 \%) & 8(72,7 \%) & 11 \\ \text { 2. Tidak } & 41(23,6) & 33(76,4 \%) & 174 \\ \text { HAP } & & & \end{array}$

5 Lama

'ersalinan

$1=$ Lama $\quad 5(15,6 \%) \quad 27(84,4 \%) \quad 32$

$:=$ normal $\quad 39(25,5 \%) \quad 14(74,5 \%) \quad \mid 53$

6 Penyakit

$\begin{array}{llll}\text { Kronis } & & 6(54,5 \%) & 11\end{array}$

$2=$ Tidak $\quad 39(22,4 \%) \quad 35(77,6 \%) \quad 174$

7 Jenis

'ersalinan

$=$ persalin

Tindakan

?= pontan
$22(21,6 \%) \quad 30(78,4 \%) \quad 102$

$22(26,5 \%) \quad 51(73,5 \%) \quad 83$
$.082 \quad 2,885$ .8359 .9 asfiksia.

60)

$1.735 \quad 1.907$

J.9313.906)

1.779

1.216

).308-

4.798)

0.2130 .541 .1951 .5

03)

Squaer didapatkan nilai P 0,280 berarti pada alpa 0,05 secara statistic tidak ada hubungan yang signifikan antara paritas dengan kejadian Hubungan ketuban pecah dini pada ibu dengan kejadian asfiksia pada bayi

Hasil penelitian diperoleh informasi Ibu yang mengalami ketuban pecah (ketuban pecah pada pase laten) sebanyak 80 orang $(43,2 \%)$ 
dan ibu yang tidak mengalami KPD sebanyak 105 orang $(56,8 \%)$

Hasil analisa bivariate sebanyak 80 orang melahirkan bayi dengan asfiksia sebanyak 20 orang $(25 \%)$ dibandingkan dengan yang tidak mengalami KPD sebanyak 105 orang melahirkan bayi asfiksia sebanyak 24 orang $(22,8 \%)$ hasil ujistatistik Chi Squaer didapatkan nilai $\mathrm{P} 0,735$ berarti pada alpa 0,05 secara statistik tidak ada hubungan yang signifikan antara ketuban pecah dini dengan kejadian asfiksia .

Hubungan Pre Eklamsi Berat (PEB) pada ibu dengan kejadian Asfiksia pada bayi

Hasil penelitian diperoleh informasi ibu yang mengalami PEB sebanyak 52 orang $(28,1 \%)$ sedangkan yang tidak mengalami PEB sebanyak 133 orang $(71,9 \%)$

Hasil analisis bivariate Ibu yang mengalami PEB sebanyak 52 orang melahirkan bayi dengan asfiksia sebanyak 17 orang $(32,7 \%)$ dibandingkan dengan yang tidak mengalami PEB sebanyak 133 orang melahirkan bayi asfiksia sebanyak 27 orang $(20,3 \%)$ hasil uji Statistik Chi Squaer didapat kan nilai P 0,735 berarti pada alpa 0,05 secara statistic tidak ada hubungan yang signifikan antara PEB dengan kejadian asfiksia

Hubungan HAP pada ibu dengan kejadian asfiksia pada bayi

Hasil penelitian diperoleh informasi dari responden sebanyak 185 orang yang mengalami
HAP sebanyak 11 orang (6\%) dan yang tidak mengalami HAP sebanyak 174 orang (94\%)

Hasil analisis bivariate Ibu yang mengalami HAP sebanyak 11 orang melahirkan bayi dengan asfiksia sebanyak 3 orang (27,3\%) dibandingkan dengan yang tidak mengalami HAP sebanyak 174 orang melahirkan bayi asfiksia sebanyak 41 orang $(23,6 \%)$ hasil ujistatistik Chi Squaer didapat kan nilai P 0,779 pada alpa 0,05 , berarti secara statistic tidak ada hubungan yang signifikan antara HAP dengan kejadian asfiksia.

Hubungan Lama Persalinan pada ibu dengan kejadian asfiksia pada bayi

Ibu yang mengalami persalinan lama sebanyak 32 orang melahirkan bayi dengan asfiksia sebanyak 5 orang $(15,6 \%)$ dibandingkan dengan yang tidak mengalami lama persalinan sebanyak 153 orang melahirkan bayi asfiksia sebanyak 39 orang $(25,5 \%)$ hasil uji statistik Chi Squaer didapat kan nilai P 0,213 pada alpa 0,05, berarti secara statistic tidak ada hubungan yang signifikan antara lama persalinan dengan kejadian asfiksia

Hubungan Penyakit kronis pada ibu dengan kejadian asfiksia pada bayi

Ibu yang mengalami penyakit kronis sebanyak 11 orang melahirkan bayi dengan asfiksia sebanyak 5 orang $(25,5 \%)$ dibandingkan dengan yang tidak mengalami lama persalinan sebanyak 174 orang melahirkan bayi asfiksia sebanyak 39 orang $(22,4 \%)$ hasil uji statistik Chi Squaer 
didapat kan nilai P 0,082 pada alpa 0,05, berarti secara statistic tidak ada hubungan yang signifikan antara lama persalinan dengan kejadian asfiksia. Uji statistic menunjukan OR 2,885 berarti ibu yang berpenyakit kronis mempunyai resiko terjadi asfiksia pada bayi 2,885 kali atau hampir tiga kali lebih besar dibandingkan dengan ibu yang tidak mengalami penyakit kronis..

Hubungan Jenis Persalinan dengan kejadian asfiksia pada bayi

Ibu yang mengalami perslinan dengan tindakan sebanyak dari 102 orang, terjadi asfiksia sebanyak 22 bayi $(21,6 \%)$ dibandingkan yang mengalami persalinan normal/spontan sebanyak 83 bayi , terjadi asfiksia sebanyak 22 bayi, $(26,5 \%)$ hasil uji statistik Chi Squaer didapat kan nilai P 0,433 pada alpa 0,05, berarti secara statistic tidak ada hubungan yang signifikan antara jenis persalinan dengan kejadian asfiksia

Hubungan umur ibu dengan kejadian asfiksia pada bayi

Ibu dengan umur resiko tiunggi sebanyak 29 orang melahirkan bayi dengan asfiksia sebanyak 8 orang $(27,6 \%)$ dibandingkan dengan ibu dengan umur resiko rendah sebanyak 156 orang , melahirkan bayi dengan asfiksia sebanyak 36 bayi, (23,1 \%) hasil uji statistik Chi Squaer didapat kan nilai P 0,600 pada alpa 0,05 , berarti secara statistic tidak ada hubungan yang signifikan antara umur ibu dengan kejadian asfiksia
Hubungan Pendidikan ibu dengan kejadian asfiksia pada bayi

Ibu dengan pendidikan rendah sebanyak,106 orang , melahirkan bayi dengan asfiksia sebanyak 31 orang $(29,2 \%)$ dibandingkan dengan ibu dengan pendidikan tinggi sebanyak 79 orang, melahirkan bayi dengan asfiksia sebanyak 13 bayi, (16,5\%) hasil uji statistik Chi Squaer didapat kan nilai $\mathrm{P} 0,043$ pada alpa 0,05 , berarti secara statistik ada hubungan yang signifikan antara umur ibu dengan kejadian asfiksia.OR 2,098 berarti ibu yang berpendidikan rendah mempunyai resiko melahirkan bayi dengan asfiksia dua kali lebih besar dibandingkan dengan ibu berpendidikan tinggi

Hubungan masa gestasi dengan kejadian asfiksia pada bayi

Bayi dengan usia kehamilan dismatur $(<37$ minggu/> dari 40 minggu) 51 bayi, terjadi asfiksia sebanyak 19 bayi dibandingkan usia kehamilan matur ( 37-40 minggu)sebanyak 134 bayi, terjadi asfiksia sebanyak 25 bayi (18,7\%) hasil uji statistik Chi Squaer didapat kan nilai $\mathrm{P} 0,008$ pada alpa 0,05 , berarti secara statistik ada hubungan yang signifikan antara masa gestasi dengan kejadian asfiksia Uji statistic menunjukan OR 2,589 berarti usia gestasi dismatur $(<37$ minggu dan $>$ 40 minggu) mempunyai resiko terjadi asfiksia pada bayi dua laki lebih besar dibandingkan dengan usia gestasi matur. 
Hubungan Berat Bayi Lahir dengan kejadian asfiksia pada bayi

Bayi dengan berat badan lahir rendah ( $<2500$ gram ) sebanyak 20 bayi, terjadi asfiksia sebanyak 12 bayi (60\%) dibandingkan dengan bayi non BBLR atau berat lebih dari 2500 gram )sebanyak 165 bayi , terjadi asfiksia sebanyak 32 bayi, (19,3 \%) hasil uji statistik Chi Squaer didapat kan nilai P 0,000 pada alpa 0,05 , berarti secara statistic ada hubungan yang signifikan antara BBL dengan kejadian asfiksia. Nilai statistic dengan OR 6.234 artinya bayi yang lahir dengan BBLR mempunyai resiko terjadi asfiksia enam kali lebih besar dibandingkan dengan bayi lahir dengan berat badan normal (> 2500 gram)

\section{HASIL ANALISIS MULTIVARIAT.}

Untuk mengetahui variabel yang paling dominan dihubungkan dengan kejadian asfiksia pada bayi baru lahir maka diperlukan Analisis Multivariat dengan mengguanakan Regresi logistik ganda. Hasil analisis bivariate korelaqsi antara variabel Indevendeen dengan kejadian Asfiksia pada bayi baru lahir dapat dilihat pada Tabel:

Tabel 5

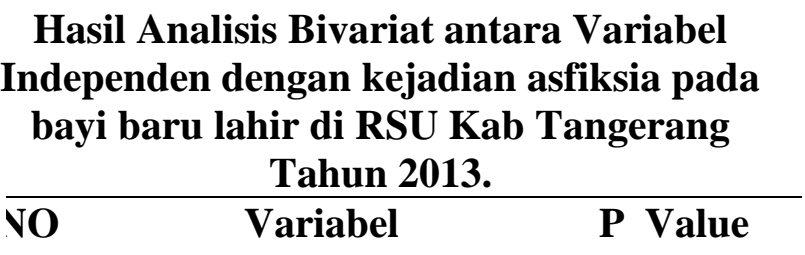

\begin{tabular}{lll}
\hline 1 & aritas & $0,091^{*}$ \\
2 & estasi & $0,109^{*}$ \\
3 & etuban Pecah Dini (KPD) & $0,093^{*}$ \\
4 & re Ekslampsi Berat (PEB) & $0,124^{*}$ \\
\hline
\end{tabular}

\begin{tabular}{lll}
\hline 5 & aemorhogik Ante Partum & 0,362 \\
& IAP) & \\
6 & ama persalinan & $0,242^{*}$ \\
7 & anyakit kronis & $0,049^{*}$ \\
8 & erat Badan Lahir & $0,003^{*}$ \\
9 & inis persalinan & $0,150^{*}$ \\
10 & Jmur ibu & 0,394 \\
11 & ingkat Pendidikan & 0,629 \\
\hline
\end{tabular}

Pada Tabel diatas menunjukan bahwa dari hasil tersebut diantara 11 variabel ada 8 variabel yang dapat masuk dalam model multivariatemempunyai nilai $\mathrm{P}<0,25$ yaitu variabel Paritas, masa gestasi, PEB, Lama persalinan, Penyakit kronis,dan BBL.

Dari seluruh proses analisis yang telah dilakukan dari 8 variabel kandidat yang diduga memiliki hubungan dengan kejadian asfiksia yang terjadi pada bayi baru lahir ternyata ada dua variabel yang secara signifikan yaitu variabel BBL dan penyakit kronis BBL dengan nilai P 0.000 dan variabel penyakit kronis 0,033

\section{Tabel 6}

\section{Hasil Analisis Multivariat Dua Variabel} Independen Menggunakan Uji Regresi Logistik Ganda Dengan Kejadian Asfiksia.

\begin{tabular}{lcccc}
\hline Variabel & B & P. Wald & $\begin{array}{c}\text { P } \\
\text { Value }\end{array}$ & $\begin{array}{c}\text { OR } \\
\mathbf{9 5 \%} \mathbf{C I}\end{array}$ \\
\hline $\begin{array}{l}\text { Penyakit } \\
\text { Krosnis }\end{array}$ & 1.366 & 4.534 & 0.033 & 3.920 \\
$\begin{array}{l}\text { Berat Badan } \\
\text { Lahir }\end{array}$ & 1.954 & 15.074 & 0.000 & 7.056 \\
\hline
\end{tabular}

Berdasarkan Tabel 6 yaitu variabel Penyakit Kronis dan berat badan lahir memiliki nilai 
$\mathrm{P}<0,05$ berarti kedua variabel tersebut berhubungan secara Signifikan dengan kejadian asfiksia pada bayi baru lahir.

Dari nilai OR bayi dengan Berat badan lahir rendah memiliki resiko kejadian asfiksi pada bayi baru lahir 7.056 kali dibandingkan dengan bayi berat badan lahir normal setelah di control oleh variabel penyakit kronis yg diderita ibu.

Selanjutnya dapat disimpulkan bahwa dari dua variabel tersebut variabel BBL merupakan variabel yang paling dominan berhubungan dengan kejadian asfiksia di Ruimah Sakit Umum Kabupaten Tangerang.

\section{PEMBAHASAN}

Hasil statistic menunjukan pendiikan ibu yang rendah menyebabkan asfiksia sebanyak 31 orang (20,9\%) dibandingkan dengan ibu yang berpendidikan tingggi melahirkan bayi asfiksia sebanyak 13 orang $(16,5 \%)$ denga nilai $\mathrm{P}=$ 0.043 dengan OR 2,098 ini berate ibu berpendidikan rendah beresiko 2.098 kali melahirkan bayi asfiksia dibandingkan dengan ibu yang berpendidikan tinggi hal ini sesuai dengan hasil kajian Sarwono prawirohardjo yang menyatakan pendidikan ibu dan perawatan masa kehamilan dan keadaan bayi yang di kandungnya, selanjutnya kementrian kesehatan menyatakan pendidikan yang tinggi akan selalu bterakses dengan informasi dengan demikian ibu mampu mendeteksi keadaan dirinya dan akan selalu berusaha mencari ppertolongan pada tenaga kesehatan sedangkan yang pendidikan rendah akan selalu pasrah dengan keadaannya
Hasil uji statistik menunjukan kejadian bayi dengan BBLR mengalami asfiksia sebanyak 12 orang (60\%) dibandingkan dengan bayi berat badan lahir normal mengalami asfiksia sebanyak 32 orang $(19,4 \%)$ dengan nilai $P$ $=0.000$ dengan OR 6,234 artinya bayi yg lahir dengan BBLR mempunyai resiko mengalami asfiksia 6,234 kali di bandingkan dengan bayi lahir dengan berat badan lahir normal sesuai dengan pendapat prawirohardjo yaitu bayi kecil untuk masa kehamilan menunjukan adanya gangguan pertumbuhan dalam uterus prognosa bayi BBLR tergantung dari berat ringannya masa perinatal diantaranya sindrom gangguan pernapasan

Hasil uji statistis menunjukan kejadian bayi dengan dismatur mengalami asfiksia sebanyak 19orang (37,3\%) dibandingkan dengan bayi yang lahir dengan masa gestasi matur mengalami asfiksia sebanyak $25(18,7 \%)$ dengan Nilai $\mathrm{P}=0.008 \mathrm{OR}$ 2,589 artinya bayi dengan lahir dismatur mempunyai resiko 2,589 kali dibandingkan dengan bayi lahir matur sesuai dengan teori prawiroharjo masa gestasi semakin muda masa gestasi semakin tinggio angka kematian akibat kejadian asfiksia Dari semua faktor yang mempunyai pengaruh secara signifikan terhadap kejadian asfiksia pada bayi setelah dilakukan uji regresi logistic ternyata factor BBLR yang paling dominan setelah di control oleh faktor penyakit kronis pada ibu. Secara teori bayi dengan BBLR mengalami lebih tinggi kejadian asfiksia dan bila kondisi ibu juga menderita penyakit kronis yang tidak terkontrol . 


\section{Kesimpulan}

Berdasarkan hasil penelitian tentang analisis factor yang mempengaruhi kejadian asfiksia di Rumah sakit Umum Kabupaten Tangerang maka dapat disimpulkan sebagai berikut

Kejadian asfiksia di Rumah sakit Umum Kabupaten Tangerang dari 185 bayi yang lahir sebanyak 44 orang bayi dan sebanyak 141 orang tidak terjadi asfiksia.

dari 11 variabel independen yang di teliti memberikan hasil secara statistik memiliki hubungan yang signifikan $(\mathrm{P}<0,05)$ dengan kejadian asfiksia pada bayi baru lahir di RSU kab Tangerang ada 3 variabel yaitu pendidikan ibu, BBLR, Masa gestasi,

hasil analisis multivariate dari 8 variabel indevenden yang di teliti, memberikan hasil secara statistic Dominan berhubungan dengan kejadian asfiksia di RSU Kab Tangerang yaitu variabel penyakit kronis dan BBLR dan variaberl yang paling dominan secara statistic adalah BBLR dengan nilai OR 7.056

\section{Referensi}

Departemen Kesehatan Direktorat Jenderal Bina Kesehatan Masyarakat. 2002. Buku Acuan Pelatihan Asuhan Persalinan Normal. Jakarta : Depkes RI.

Mansjoer, Arif (et al). 2001. Kapita Selekta Kedokteran Jilid 1. Jakarta : Media Aesculapius.

Manuaba, IBG. 1998. Ilmu Kebidanan, Penyakit Kandungan dan Keluarga
Berencana Untuk Pendidikan Bidan. Jakarta : EGC

Menteri Kesehatan RI dr. Nafsiah Mboi, SpA, MPH (16 Maret 2013) dalam pencapaian target MDGs tahun 2015 tentang AKB

Mochtar, Rustam. 1998. Sinopsis Obstetri : Obstetri Fisiologi, Obstetri Patologi Jilid I. Jakarta : EGC

Notoatmodjo, Soekidjo. 2005. Metodologi Penelitian Kesehatan. Jakarta: Pt RINEKA CITRA

Nurchotimah 2008 asfiksia pada bayi baru lahir ,http//kalbe.co.id diakses 06 -05 2013 jam 1600

Prawirohardjo, Sarwono. 2002. Ilmu Kebidanan. Jakrta : YBP-SP

Ramali, MH. 2003. Kamus Kedokteran. Jakarta : Djambatan

Saifuddin, Abdul Bari (ed). 2002. Buku Acuan Nasional Pelayanan Kesehatan Maternal dan Neonatal. Jakarta : YBP-SP

SKRT, 2001 (Profil Kesehatan Indonesia Tahun 2010)

William. 2005. Obstetri Edisi 21. Jakarta 